\title{
A comparative study on the microstructural and antibacterial properties of Laser - textured and SLA dental implants.
}

\author{
Ronald Motzfeld ${ }^{1}$, Cristian Covarrubias ${ }^{2 *}$, Leyla Gómez ${ }^{3}$, Fabiola Bastias², Miguel Maureira²
}

\begin{abstract}
1. Department of Restorative Dentistry, Faculty of Dentistry, University of Chile, Santiago, Chile. 2. Laboratory of Nanobiomaterials, Research Institute of Dental Sciences, Faculty of Dentistry, Independencia, University of Chile, Santiago, Chile. 3. Laboratory of Microbiology, Department of Pathology, Faculty of Dentistry, University of Chile, Santiago, Chile.
\end{abstract}

* Corresponding author: Cristian Covarrubias | Address: Sergio Livingstone 943, Independencia, Santiago, Chile. | Phone: +56 2 29781719; fax: +56 229781754 | E-mail: ccovarrubias@odontologia. uchile.cl

Work received on 31/07/2020

Revised work 28/01/2021

Approved for publication on 06/03/2021

\begin{abstract}
Objective: To compare the structural and antibacterial properties of a Laser - treated commercial dental implant (No-ltis ${ }^{\circledR}$ ) with those of a traditional sandblasted and acidetched (SLA) implant. Materials and Methods: Surface topography and elemental composition of the implant surfaces were analyzed by using scanning electron microscopy (SEM) coupled to dispersive X - ray spectrometry (EDX). The antibacterial properties of the implants were tested against Aggregatibacter actinomycetemcomitans. Protein adsorption capacity and bioactivity in simulated body fluid (SBF) of the implant surfaces were also analyzed. Results: The Laser - treated implant presents a topography constituted by smooth and uniform concavities of $\sim 30 \mu \mathrm{m}$ in diameter, free of Laser - induced alterations, and impurity elements. The Laser - textured surface demonstrated to significantly $(p=0.0132)$ reduce by up to around $61 \%$ the bacterial growth as compared with the SLA implant, which was found to be associated to a reduced adhesion of proteins on the Laser surface. No apatite - related mineral deposits were detected on the SBF - incubated surfaces. Conclusion: The smooth Laser designed surface exhibits an antimicrobial effect that decreases the growth of bacterial biofilm on its surface, which could contribute to reduce the risk of peri-implantitis.

KEY WORDS

Laser - textured implants; Peri-implantitis; Antimicrobial surfaces.
\end{abstract}

Int. J. Inter. Dent Vol. 14(3); 222-225, 2021.

\section{INTRODUCTION}

The success of oral rehabilitation using titanium dental implants is largely dependent on the degree of osseointegration at the metal-bone interface as well as the management of peri-implant infections. In this respect several surface modification techniques of titanium implants have been used as strategy to improve the osseointegration properties and prevent infections. Peri-implantitis is the inflammatory disease marked by bacterial infection and the destructive process affecting the soft and hard tissues around osseointegrated implants, leading to the loss of supporting bone ${ }^{(1,2)}$. To reduce the biofilm formation on implant surface, antibacterial coatings loaded with antibiotics ${ }^{(3)}$, chlorhexidine ${ }^{(4)}$, or silver nanoparticles ${ }^{(5)}$ have been explored. Other approach consists in the design of titanium implants with different surface textures and topographies. Reduced roughness and surface free energy on implants has shown a positive correlation with the inhibition of bacterial adhesion ${ }^{(6)}$. Thus, different techniques are studied and used to fabricate titanium dental implants with controlled texture including smooth-machined, sand-blasted, acid-etched, and plasma-sprayed surfaces. Laser melt and modify the texture of titanium implants, producing extremely pure, ordered, and uniform surfaces ${ }^{(7,8)}$. Laser texturing replaces a random process (e.g., blasting, etching) with a digital one. Pulses of laser light allow a titanium implant surface to be structured with a precise, repeatable pattern and enables both product designers and manufacturers to design in and meet more exacting specifications for roughness. Currently, dental implants with a robot-manipulated laser surfaces are being introduced to the market ${ }^{(9)}$. Laser-designed surfaces have been proposed to improve the mechanical, chemical, and biological properties of dental implants. Surface topographies may promote cell attachment and differentiation, thus improving the osseointegration properties ${ }^{(10)}$. Also, smoother surfaces produced by Laser treatment have been proposed to reduce the biofilm formation and consequently decrease the risk of peri-implantitis ${ }^{(11)}$. However, scant evidence exists on the antimicrobial properties of Lasertextured implants against peri-implant pathogens as well as comparative studies with irregular surfaces produced through conventional surface treatments.

In this work, the structural, compositional, and antibacterial properties of a Laser-treated commercial implant are systematically compared with that of a sandblasted and acid-etched (SLA) implant. Antibacterial properties are assessed against Aggregatibacter actinomycetemcomitans, a representative peri-implant bacterium ${ }^{(12)}$.

\section{MATERIALS AND METHODS}

The current work corresponds to a quantitative, qualitative, and comparative in vitro experimental study.

Surface characterization of dental implants.

Single piece dental implants (Ihde Dental AG, Switzerland) fabricated with titanium alloy grade 5 (Ti6Al4V-ELI) were studied. Laser-textured (No-ltis ${ }^{\circledR}$ ) (Laser) and traditional double - sandblasted/acid-etched (SLA) implants were compared. The dental implants had an endossal implant thread of $3.2 / 3.7 \mathrm{~mm}$ and endossal length of $15 \mathrm{~mm}$.

Surface topography of implants was analyzed by scanning electron microscopy (SEM) in a JEOL JSM-IT300LV microscope. Representative SEM images were acquired at $30,120,350$, and $800 \mathrm{X}$ of magnification with an accelerating voltage of $20 \mathrm{kV}$. Atomic-resolution compositional mapping on the implant surfaces was performed by energy dispersive X-ray spectrometry (EDX) (Aztec EDS, Oxford Instruments) coupled to the SEM microscope. The surfaces of a total of five implants of each type were analyzed, and representative SEM images of them are presented.

\section{Antibacterial activity}

The growth of Aggregatibacter actinomycetemcomitans serotype b (ATCC ${ }^{\circledR} 43718^{\text {TM }}$ ) was assessed on the implant surfaces. Each sterilized implant was vertically placed in tubes with $990 \mu \mathrm{L}$ of fresh Brain Heart Infusion (BHI) and $10 \mu \mathrm{L}$ of the inoculum (adjusted to 2 McFarland standard), and incubated for 48 hours in a $5 \% \mathrm{CO}_{2}$ atmosphere at $37^{\circ} \mathrm{C}$. After the incubation period, the implants were removed from the growth medium and immersed into a $1 \%$ Tween 80 saline solution to remove the adherent bacteria. The, dilutions taken from the bacterial suspensions were plated onto $\mathrm{BHI}$ agar and incubated for $48 \mathrm{~h}$ at $37^{\circ} \mathrm{C}$. After that, the colonies were counted and the colony forming units per implant surface $\left(\mathrm{CFU} / \mathrm{mm}^{2}\right)$ were calculated.

Bacterial biofilm formed on each implant surface was examined by SEM microscopy. After incubation period, adherent bacteria were fixed by immersing the implants in $2.5 \%$ glutaraldehyde, then dehydrated in ethanol series, dried in supercritical $\mathrm{CO}_{2}$ (Tousimis, Autosamdri-815) and gold coated prior to SEM imagining.

\section{Protein adsorption}

The protein adsorption capacity of the dental implant surfaces was determined by using bovine serum albumin (Merck) as model protein. 
$1.5 \mathrm{~mL}$ of buffered solution ( $\mathrm{pH} 7.4, \mathrm{~K}_{2} \mathrm{HPO}_{4} / \mathrm{KH}_{2} \mathrm{PO}_{4} 100 \mathrm{mM}$ ) containing $0.4 \mathrm{mg} / \mathrm{mL}$ of protein was contacted with each implant vertically placed in a 24 -well cell culture plate. After $6 \mathrm{~h}$ of incubation at $37^{\circ} \mathrm{C}$, the implants were removed from the protein solution and washed with phosphate buffer to remove the nonadherent proteins. Then, the adhered proteins were extracted from the implant surfaces by incubating with $1.5 \mathrm{~mL}$ of $2 \%$ sodium dodecyl sulfate solution for $12 \mathrm{~h}$ at $37^{\circ} \mathrm{C}$. The concentration of extracted protein was measured using the colorimetric Micro Bicinchoninic Acid Assay Kit (Thermo Scientific).

\section{Surface bioactivity assay}

The ability of implant surface to form bone -like apatite in acellular simulated body fluid (SBF) was evaluated according to ISO/FDIS 23317:2007 (E). The Kokubo's SBF solution pH 7.4 was prepared with the ionic composition and procedure described elsewhere ${ }^{(13)}$. The implant samples were individually immersed in $50 \mathrm{~mL}$ of SBF in polyethylene bottles at $36.5^{\circ} \mathrm{C}$ in a thermostatic shaking water bath. After 28 days of incubation, the implants were removed from SBF, immersed in distilled water for $3 \mathrm{~min}$, and dried at $60^{\circ} \mathrm{C}$. The apatite mineralized on the implant surfaces was analyzed by SEM and EDX compositional measurements.

\section{Statistical analysis}

Statistical analysis of colony forming unit counting data was carried out by using GraphPad prism 6 (GraphPad Software, San Diego, CA). Oneway analysis of variance with post hoc multiple comparisons (Tukey's test) was performed on a minimum of $n=5$ (significance level, $P<0.05$ ).

\section{RESULTS}

Fig. 1 presents the SEM images of the dental implant surfaces acquired with different magnification. The Laser - treated implant exhibits a topography constituted by uniform and circular concavities of $\sim 30 \mu \mathrm{m}$ in diameter and $\sim 2 \mu \mathrm{m}$ of border width, which are regularly distributed on the entire implant surface. The inner and outer area of the concavities present a smooth texture and free of porosity or other Laser - induced alterations. In contrast, the SLA implant exhibits a disorganized, rough, and uneven surface. EDX elemental analysis (Fig. 2) confirmed the presence of Ti, Al, $\mathrm{V}$ and $\mathrm{O}$ as main components of the oxidized Ti6Al4V implant surfaces. $\mathrm{C}$ $\mathrm{Ca}$, and $\mathrm{P}$ were detected as minor or trace components of the surfaces.
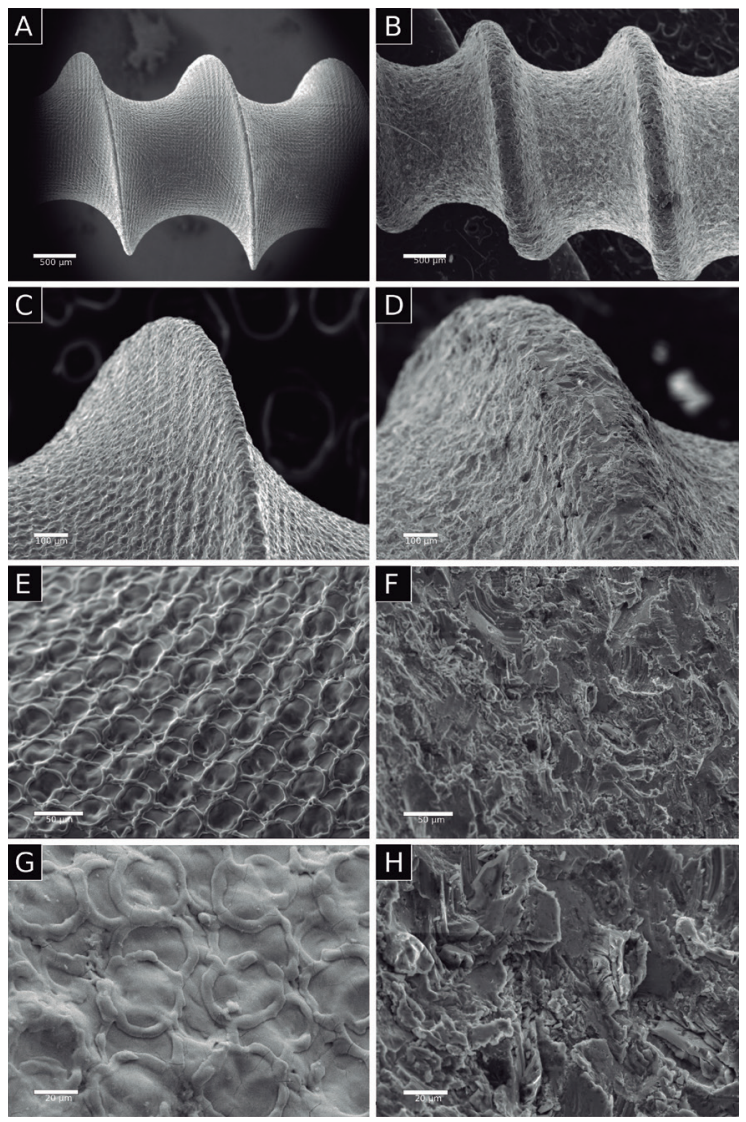

Figure 1. SEM images of titanium dental implant surfaces of Laser (A, B and $\operatorname{SLA}(C, D)$ at $30 X$ of magnification and Laser $(E, F)$ and SLA $(G, H)$ at 800X of magnification.
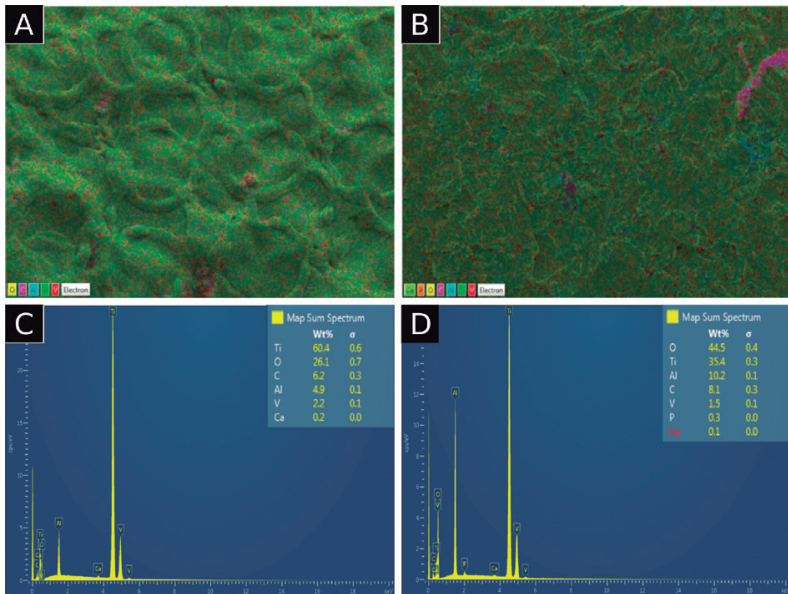

Figure 2. EDX compositional analysis of the dental implant surfaces. EDX elemental distribution maps on the Laser (A) and SLA (B) implant surfaces. EDX spectra showing the weight percentage values of present elements on the Laser (C) and SLA (D) implant surfaces.

The survival of $A$. actinomycetemcomitans biofilm grown per area of implant surface is shown Fig. 3. The results show that bacterial survival is significantly $(p=0.0132)$ reduced by up to around $61 \%$ on the Laser - treated implant surface as compared with the traditional SLA implant surface. SEM images (Fig. 4) confirm a substantially lower amount of bacterial biofilm developed on the Laser implant. Abundant microcolonies anchored to the surface and apparently embedded in their exopolysaccharide matrix ${ }^{(14)}$ can be observed on the SLA implant (white arrows, Fig. 4h).

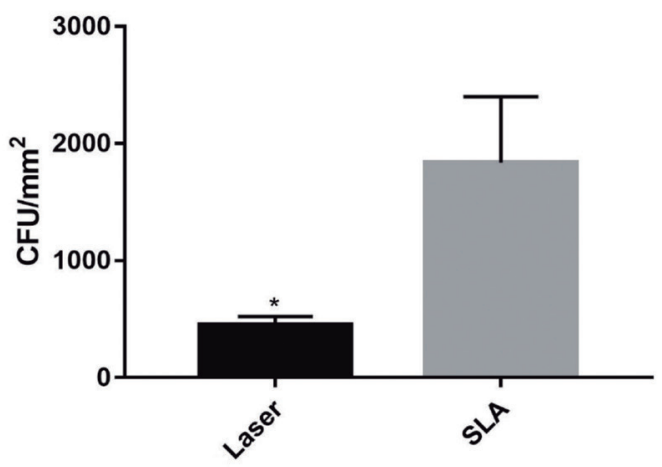

$p=0.0132$

Figure 3. Survival de A. actinomycetemcomitans biofilm grown per area of implant surface after 48 hours of incubation using a 2 McFarland standard. Each value is mean $\pm s d(n=5)$. * indicates $p<0.05$.

The albumin protein adsorption capacities for the Laser and SLA implant surfaces were $390 \mathrm{ng} / \mathrm{mm} 2$ and $540 \mathrm{ng} / \mathrm{mm} 2$, respectively.

Fig. 5 shows SEM images and EDX compositional mapping of the implant surfaces after 28 days of immersion in SBF. Although the implant textures appear to be slightly modified, no apatite deposits or related minerals were detected on the surfaces. The $\mathrm{Ca}$ and $\mathrm{P}$ contents measured by EDX were not significant.

\section{DISCUSSION}

The topography, chemical composition, and bioactive properties of the Laser - textured implant surface was analyzed and systematically compared with that of a traditional SLA implant. The results confirm that the Laser implant presents a highly regular and smooth surface according to the information provided by the manufacturer, which contrast with the disorganized and rough surface of the SLA implant. Laser treatment also showed to produce topographical modifications of the implant surface without altering its surface chemical composition.

Microbiological assays demonstrated that the Laser implant exhibits 

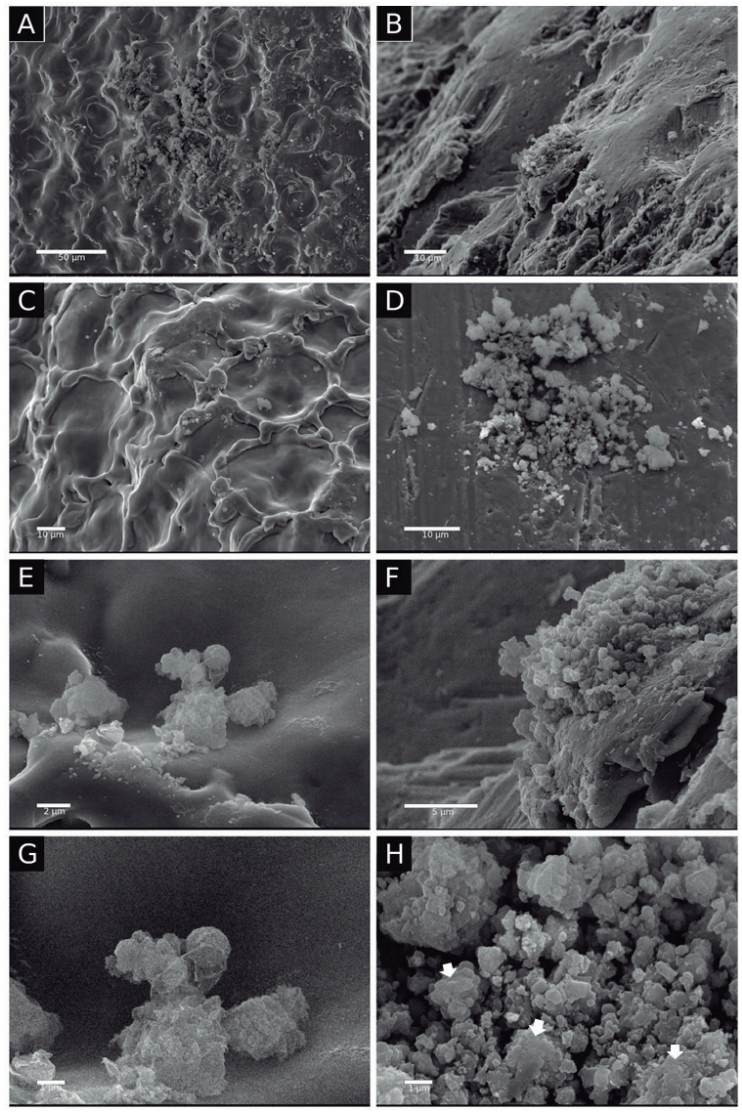

Figure 4. SEM images of $A$. actinomycetemcomitans biofilm grown on Laser implant surface at 500X (A), 1,000X (C), 6,000X (G) and 10,000X (E) of magnification and on the SLA implant surface at 1,500X (B), 2,000X (D), 5,000X (F), 10,000X $(\mathrm{H})$ of magnification. White arrows in $\mathrm{H}$ show the characteristic morphology of bacteria embedded in exopolysaccharide matrix.
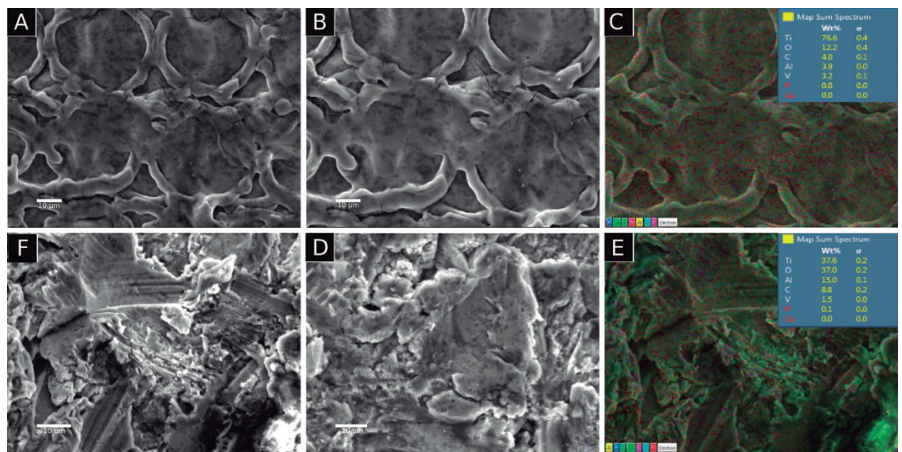

Figure 5. SEM images and EDX compositional mapping of Laser implant surface $(A-C)$ and SLA implant surface $(F-E)$ after 28 days of incubation in SBF at $37^{\circ} \mathrm{C}$. Images were taken at $1,100 \mathrm{X}$ and $1,400 \mathrm{X}$ of magnification.

high antibacterial activity against a representative peri-implant bacterium as compared to the SLA implant. The reduced number of bacteria grown the Laser - textured implant surface was verified by counting of viable bacteria and through of SEM observations. The smoother surface of
Laser implant significantly decreases the bacterial attachment and biofilm formation on the implant. The biofilm formation on implant surface strongly depends on the previous adsorption of water molecules and proteins ${ }^{(15)}$, which promote the bacterial colonization. In the current study, Laser designed implant surface exhibited a lower protein adsorption capacity as compared to the SLA. These results indicate that lower free energy provided by the smooth Laser surface decreases the protein attachment and consequently, the biofilm formation. In contrast, the irregularities of the rough SLA implant surface promote higher protein adsorption, which facilitates the biofilm establishment. Although smooth implant surfaces have been suggested for resisting bacterial colonization ${ }^{(16)}$, this effect have been scantly verified on commercial dental implants fabricated with Laser texturing technology. Uhlman et al.(17) detected with crystal violet staining a reduced attachment of Streptococcus mutans on laser microtextured titanium surfaces. Zwahr et al. ${ }^{(18)}$ used laser processing to produce hierarchical patterns on titanium sheets, which were able to reduce the adherence of Escherichia coli. Ionescu et al. ${ }^{(19)}$ studied a laser-designed titanium surface regularly formed by 18 - $20 \mu \mathrm{m}$ micropits, which shown to reduce the formation of a nonspecific biofilm from saliva. Therefore, most of the reported studies on Laser surfaces did not consider specific peri-implant pathogens such as Porphyromonas gingivalis or A. Actinomycetemcomitans. Lasserre et al. ${ }^{(20)}$ found that these bacteria present similar frequency in both peri-implantitis and periodontitis conditions. Although the antimicrobial capacity of the Laser - treated implants strongly will depend on the structural characteristics generated on its surface, in vitro antibacterial properties of the Laser implant found in the current study could contribute to reducing the probabilities of infection. Our study also had some limitations. Antibacterial activity of the implant surfaces was measured by using a single bacteria biofilm model, however peri-implant microbiome has been characterized by 71 species, with 12 of them enriched in peri-implantitis diseased sites $^{(21)}$. So, further studies could be performed by using multibacteria biofilms models. In addition, antibacterial effectiveness of the Laser-textured implant surface should be confirmed through both in vivo animal testing and clinical trials.

On the other hand, no mineralization of bone-like apatite was detected on the implant surfaces by using the standard acellular SBF assay. Therefore, the micro-and nano-scale analysis of the osseointegration properties of the Laser implant would require further in vitro and in vivo biological experiments, including cell differentiation assays and animal models.

\section{CONCLUSIONS}

The dental implant fabricated by laser texturing technology is constituted by regular and smooth surface topography. The smooth Laser - treated surface exhibits antibacterial properties that decrease the growth of bacterial biofilm, which was found to be associated with a reduced adsorption capacity of bacterial adhesion proteins. Thus, the Laser implant could contribute to decrease the risk of dental peri-implant infection.

\section{CLINICAL RELEVANCE}

The current study compares the structural and antibacterial properties of a Laser - treated commercial dental implant (No-ltis ${ }^{\circledR}$ ) with those of a traditional sandblasted and acid-etched (SLA) implant. The results demonstrated that implant with Laser - treated has a regular and smooth titanium surface that significantly reduce the bacterial growth as compared with that of a traditional SLA implant. These findings suggest that the antibacterial properties exhibited by the dental implant with smooth Laser-designed surface could contribute to reduce the risk of peri-implant infection, which is one the main reasons of dental implant failure.

\section{CONFLICT OF INTERESTS.}

The authors declare that they have no conflict of interest. 


\section{References}

1. Mombelli A. Microbiology and antimicrobial therapy of peri-implantitis. Periodontol 2000. 2002;28:177-89.

2. Esposito M, Hirsch J, Lekholm U, Thomsen P. Biological factors contributing to failures of osseointegrated oral implants (II). Etiopathogenesis. Eur J Oral Sci. 1998;106(3):721-64

3. Lingzhou Z, Chu PK, Zhang Y, Wu Z. Antibacterial coatings on titanium implants. J Biomed Mater Res B Appl Biomater. 2009;91(1):470-80.

4. Campbell AA, Song L, Li XS, Nelson BJ, Bottoni C, Brooks DE, et al. Development, characterization, and anti-microbial efficacy of hydroxyapatitechlorhexidine coatings produced by surface-induced mineralization. J Biomed Mater Res. 2000;53(4):400-

5. Massa MA, Covarrubias C, Bittner M, Fuentevilla IA, Capetillo P, Von Marttens A et al. Synthesis of new antibacterial composite coating for titanium based on highly ordered nanoporous silica and silver nanoparticles. Mater Sci Eng C Mater Biol Appl. 2014;45:146-53.

6. Wassmann T, Kreis S, Behr M, Buergers R. The influence of surface texture and wettability on initial bacterial adhesion on titanium and zirconium oxide dental implants. Int J Implant Dent. 2017;3(1): 32.

7. Semak VV, Dahotre NB. Laser Surface Texturing. In: Dahotre NB (eds) Lasers in Surface Engineering. Park: ASM International; 1998 p. 35-67.

8. Gaggl A, Schultes G, Muller WD, Karcher H. Scanning electron microscopical analysis of laser-treated titanium implant surfaces. A comparative study. Biomaterials 2000;21(10):1067-73.

9. Dr. Ihde Dental AG. IHDEDENTAL [Internet]. [cited 2020 Apr 28]. p. 2020. Available from: https://implant.com/en/\#produkte

10. Smeets R, Stadlinger B, Schwarz F, et al. Impact of dental implant surface modifications on osseointegration. Biomed Res Int. 2016;2016:6285620.

11. kokubo T, Kushitani H, Sakka S, Kitsugi T, Yamamuro T. Solution able to reproduce in vivo surface-structure change in bioactive glass-ceramic A-W. J Biomed Mater Res. 1990;24(6):723-34.

12. Cortelli SC, Cortelli JR, Romeiro RL, Costa FO, Aquino DR, Orzechowski PR, et al. Frequency of periodontal pathogens in equivalent peri-implant and periodontal clinical statuses. Arch Oral Biol. 2013;58(1):67-74

13. Seghal Kiran G, Priyadharshini S, Anitha K, Gnanamani E, Selvin J. Characterization of an exopolysaccharide from probiont Enterobacter faecalis MSI12 and its effect on the disruption of Candida albicans biofilm. RSC Adv. 2015:5:71573-85

14. Di Giulio M, Traini T, Sinjari B, Nostro A, Caputi S, Cellini L. Porphyromonas gingivalis biofilm formation in different titanium surfaces, an in vitro study. Clin Oral Impl Res. 2016;27(7):918-25.

15. Singh AV, Vyas V, Patil R, Sharma V, Scopelliti PE, Bongiorno G, et al. Quantitative characterization of the influence of the nanoscale morphology of nanostructured surfaces on bacterial adhesion and biofilm formation. PLoS ONE 2011;6(9):e25029. 16. Grossner-Schreiber B, Griepentrog M, Haustein I, Muller WD, Lange KP, Briedigkeit $\mathrm{H}$, et al. Plaque formation on surface modified dental implants. An in vitro study. Clin Oral Implants Res. 2001;12(6):543-51.

17. Uhlmann E, Schweitzer L, Kieburg H, Spielvogel A, Huth-Herms K. The effects of laser microtexturing of biomedical grade 5 ti-6al-4v dental implants (abutment) on biofilm formation. Procedia CIRP 2018;68:184-9.

18. Zwahr C, Helbig R, Werner C, Lasagni A. Fabrication of multifunctional titanium surfaces by producing hierarchical surface patterns using laser-based ablation methods. Sci Rep. 2019;9(1):6721.

19. Ionescu AC, Brambilla E, Azzola F, Ottobelli M, Pellegrini G, Francetti LA. Laser microtextured titanium implant surfaces reduce in vitro and in situ oral biofilm formation. PLoS ONE. 2018;13(9):e0202262.

20. Lasserre J, Brecx M, Toma S. Oral microbes, biofilms and their role in periodontal and peri-implant diseases. Materials. 2018;11(10):1802.

21. Ghensi P, Manghi, P, Zolfo M, Armanini F, Pasolli E, Bolzan M, et al. Strong oral plaque microbiome signatures for dental implant diseases identified by strainresolution metagenomics. NPJ Biofilms Microbiomes. 2020;6(1):47. 